\title{
Scheduling Challenges within Maintenance Repair and Overhaul Operations in the Civil Aviation Sector
}

\author{
Salah Albakkoush, Emanuele Pagone*, Konstantinos Salonitis \\ Sustainable Manufacturing Systems Centre, School of Aerospace, Transport and Manufacturing, Cranfield University, Cranfield, \\ Bedfordshire, MK43 OLR, United Kingdom \\ * Corresponding author. Tel.: +44-1234-754608. E-mail address: e.pagone@cranfield.ac.uk
}

\begin{abstract}
Aircraft Maintenance Repair and Overhaul (MRO) corporations provide two types of service: light and heavy maintenance. Typical MRO problems are related to scheduled and unscheduled aircraft maintenance because of the large number of components and parts that need a lead-in time for delivery and the consequent scheduling of work. This paper focuses on the significant causes of such problems affecting MRO operations. It addresses three major factors as follows: OEMs, Maintenance schedule and manpower and turnaround time. By a systematic review and analysis of scientific literature sources, it is shown that aviation industry standards do not permit aircraft to be scheduled unless they are maintained according to and comply with the stringent standards related to airworthiness. What seems to be important is effective maintenance schedule planning since this reduces time and cost, and enables aircraft to be maintained in a short time. Unfortunately, light maintenance remains beyond the control of airlines because no time allowance is programmed into flight schedules for such events vs increase the number of flight schedule per day.
\end{abstract}

Keywords: Maintenance schedule, OEMs, Manpower, Turnaroud time

\section{Introduction.}

Maintenance, repair and overhaul (MRO) in the aviation industry is a process with differing requirements, defined by aircraft manufacturers and airworthiness authorities to provide safety for airline staff (stewards, pilots, etc.) and customers (i.e. passengers). Airline companies spend billions of dollars per year servicing their aircraft and in doing so, engage the services of MRO companies to provide a high standard of maintenance and service that is also affordable. That is making MRO companies increase their revenue up to $45 \%$ from 1990 to 2012 [1].

Original Equipment Manufacturers (OEMs) supply spare parts to MRO companies for aircraft servicing, and MRO organizations seek to achieve an optimal balance among employees, machine resources and maintenance components [2]. However, unexpected events such as aircraft component failure lead to unscheduled maintenance that requires the aircraft to stay longer on the ground, increasing turnaround times [3].

Due to the nature and demand of their work, MRO companies face challenges related to scheduling, which can affect their operations, due primarily to the large number of maintenance checklists to complete every day. Although guidance on maintenance schedules is normally issued by the manufacturer, airline operators can decide when aircraft go for maintenance checks. This decision has prompted MRO companies to amend their operational scheduling plan of aircraft maintenance routing, which costs time for MRO operators to build a new maintenance strategy. This is a critical issue facing MRO operations as different aircraft types require different checklists, making the maintenance system harder to control, especially for a number of maintenance operators who need to service the aircraft. The core focus of this paper is to investigate the most critical factors which have an impact on MRO operation, by assessing how and why these factors arise. The findings of this study may help MRO companies develop their strategy to more efficiently offer aircraft servicing without delays.

\section{Methodology}

In the context of this paper, the meaning of categorization refers to understanding the nature of the business service; this method is built and based on degree and type of change. It is through these changes that the authors' research will highlight a gap in existing work in this field, which is a critical element that effects service. In order to improve the quality of the literature review, it is necessary to analyze and evaluate different categories, since this will identify similar findings in the same research area. [4]. However, the use of different categories 
might affect the quality of research, particularly when researchers are studying different elements in the same field or area. Furthermore, different authors have encountered similar finding by using different methodologies, or various other tools [5].

The methodology of this study was to focus on the titles and keywords that referred to MRO operation. The initial phase focuses specifically on gaining a contextual understanding of the literature review, which has concluded that the major causes of maintenance scheduling problems influencing MRO companies include OEMs, Aircraft maintenance schedule manpower and turnaround time. The literature review conducted in this study has focused on the titles and keywords that referred to MRO operations. Fig. 1. shows the research process.

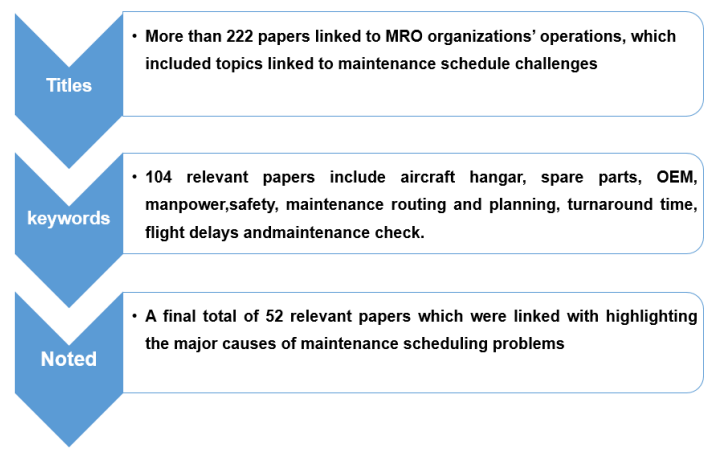

Fig. 1. Description of the major research process steps.

It was noted that some articles repeated the same ideas and some used ideas against safety requirements. This led to a further narrowing of articles to leave a final total of 52 relevant papers. Specifically, 14 papers focused on OEM suppliers, 7 papers on manpower, 8 papers on flight delays, 15 papers on maintenance schedule and 8 papers on turnaround time.

Firstly, MRO marketing had been studied by authors to show MRO companies' revenue, moving on to aircraft maintenance checks. Based on a revision of aircraft maintenance checks, the writers determined those factors required for study. They included OEMs, aircraft maintenance schedules, and manpower and turnaround time. These factors emerged from the findings of previous researchers and the methodologies adopted by them to determine aspects that significantly affect the operation of MRO companies. Moreover, comparing the different findings of the researchers used in the review and their respective methodologies in the same areas helped the authors of this study determine the most common factors which may affect the operations of MRO companies. According to previous research conducted, the issue of MRO companies' operations was identified as a very complex task because a total of five factors showed in the literature review, all of which may affect their operations. These factors were therefore separated based on the relationship between them, i.e. factors sharing the same area, same methods used in the research study and by the number of research findings mentioned by the researchers.

Fig. 2 shows the number of categorized papers that list factors which affect MRO operation.

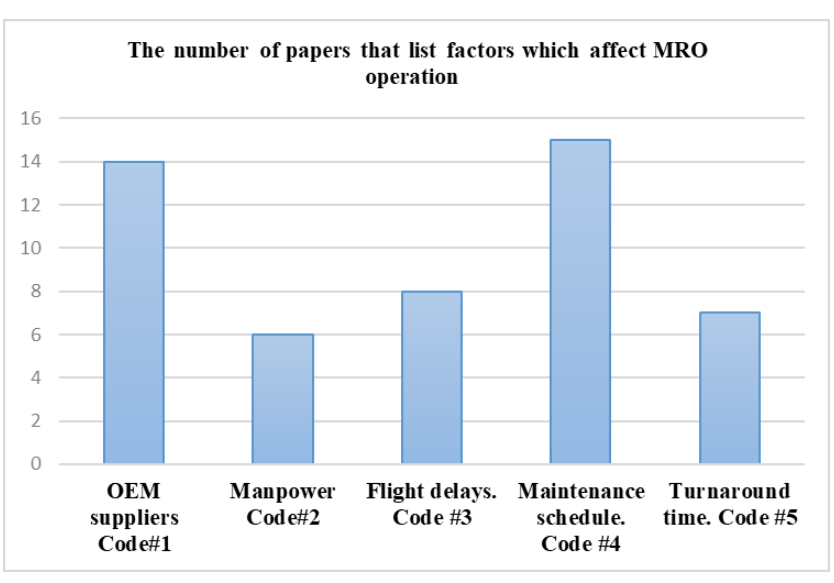

Fig. 2. Categorization of papers that study the factors that influence MRO operations

Tab. 1 shows researchers' methodology uses on their studies in Fig. 2.

Table 1. Researchers' methodology uses on their studies

\begin{tabular}{lllll}
\hline Factors & $\begin{array}{l}\text { Case } \\
\text { study }\end{array}$ & Interviews & Models & Simulation \\
\hline$\# 1$ & 2 & 5 & 5 & 2 \\
$\# 2$ & 1 & 3 & 2 & 0 \\
$\# 3$ & 3 & 0 & 3 & 0 \\
$\# 4$ & 3 & 2 & 11 & 3 \\
$\# 5$ & 1 & 1 & 4 & 1 \\
\hline
\end{tabular}

This methodology aims to present challenges for MRO companies, which are considered in the next section.

\section{Scheduling Challenges within MRO Operations.}

This section discusses the challenges faced by MRO companies in terms of how they service aircraft during the maintenance period. These challenges include OEMs, Aircraft maintenance schedule, and manpower and turnaround time. A fishbone diagram (Fig. 3) highlights the key issues faced by MRO companies and provides the overall context for this study, as well as the rationale for the research gap. 
Looking at Fig. 3, there are a number of major problems that represent a challenge to the maintenance schedule, which are considered in the next four sub-sections.

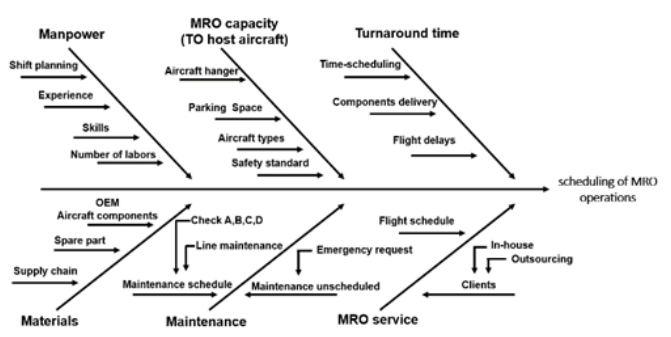

Fig. 3. Fishbone diagram summarizing the research findings

\subsection{Original equipment manufacturer suppliers}

The collaboration between MRO companies and OEMs is robust; however, MRO companies response can be directly affected by the availability of spare parts and tools. They can also be affected indirectly, for example, due to lack of heavy tools (such as Aircraft Pushback) since each type of aircraft requires a different, tailored, one [6]. However, when the OEM suppliers need to deliver spare parts to MRO companies, the gaps in the market for outsourced spare parts might encourage counterfeit trade; a factor that inevitably affects safety standards and demands within MRO companies. It is clear therefore that any gaps in the market between MRO and OEM companies may unfortunately offer an opportunity to less scrupulous suppliers involved in counterfeiting operations [7].

Another issue is the OEM organization system, especially on supply chain. The supply chain for OEM companies typically operates on an open system, particularly when MRO companies or airline operators are requesting spare parts based on their own designs. For example, redesigning seat buckles, resulting in more than 3 million liters of fuel saving during the whole period of the aircraft's life [8]. However, MRO companies may wait around a year to receive spare parts because the standard lead time for creating spare parts is around six months. That is making the aircraft takes space of MRO companies which is causing a lack of space for hosting a new aircraft and scheduling problem [9]. The assembly of aircraft spare parts itself is time consuming due to the different stages involved in this process. These stages can start with delivery of the spare part components, moving on to testing and part production which must be of a high quality and to stringent safety standards. That is challenging MRO companies to optimize spare parts inventory management and reduce overheads [10]. On another hand, Elements of aircraft maintenance such as engines and landing gear are supplied by OEM companies which operate under airplane assembly manufacturers (such as Airbus and Boeing). The challenge for the OEM organization, therefore, is not solely concerned with the delivery of maintenance equipment. Rather, they have to also be mindful of their own performance and ability to supply spare parts and materials on time without delay [11]. This OEM organization presents challenges for MRO companies that led authors to study maintenance process through aircraft maintenance schedule.

\subsection{Aircraft maintenance schedule.}

Generally, aircraft maintenance schedule is divided into two types: natural and unnatural maintenance schedule. Natural maintenance schedule refers to examining aircraft history, flight cycles or flight hours. Table 2 gives an example of natural maintenance schedule planed [12].

Table 2. Natural maintenance schedule planed [12].

\begin{tabular}{lllll}
\hline $\begin{array}{l}\text { Aircraft } \\
\text { type }\end{array}$ & $\begin{array}{l}\text { A- } \\
\text { check }\end{array}$ & $\begin{array}{l}\text { B- } \\
\text { check }\end{array}$ & C-check & $\begin{array}{l}\text { D- } \\
\text { check }\end{array}$ \\
\hline $\begin{array}{l}\text { B737- } \\
500\end{array}$ & 275 & 825 & $18 \mathrm{MO}$ & $48 \mathrm{MO}$ \\
A320 & 600 & 825 & $18-$ & \\
& FH & FH & $12 \mathrm{MO} / 3000 \mathrm{FC}$ & \\
ATR42- & $300-$ & 825 & $3000-4000 \mathrm{FH}$ & $96 \mathrm{MO}$ \\
300 & 500 & FH & & \\
& FH & & &
\end{tabular}

Based on aircraft history, flight cycles or flight hours, maintenance operators will organize aircraft checks. In contrast, unnatural aircraft maintenance checks refer to unexpected failure of aircraft components due to the expiry of parts, inefficiencies linked to maintenance operators, etc. This type of maintenance is invariably too late in the process for maintenance operators to avoid aircraft damage. That led maintenance operators to use software for aircraft components, however, EASE part 145 (ICAO appendices 1 to 8 ) recommends that maintenance operators should not use sensors or software that might affect or compromise aircraft safety [13].

Maintenance planning consists of many protocols that operators should follow. The key problem for MRO companies is unscheduled maintenance which is caused by aircraft damage. During the repair process, the maintenance operators will evaluate the damage to the aircraft and then the MRO Company will order the components needed. 
These conclude unscheduled maintenance and human resources are significant problems that impact the operation of MRO organizations [14].

Furthermore, aircraft maintenance checklists involve all aircraft details including location of spare parts and aircraft assembly/disassembly points. This can be a lengthy process causing aircraft maintenance scheduling challenges due to the complexities associated with routing that includes long-term and maintenance capacity planning [15]. Maintenance schedule is also affected by the availability of manpower during the aircraft checks, which is considered in the next section.

\subsection{Manpower}

To ensure that a correct and consistent strategy for aircraft maintenance scheduling is adopted, the skills of operators must be developed to deal with the maintenance schedule effectively. Aircraft maintenance companies recommend that in order to focus on an optimal training schedule, maintenance operators should be trained twice a year in different seasons to avoid any weaknesses in operators' size and improve their knowledge [16].

Work-hours per check are also considered by aircraft maintenance companies as part of their maintenance system planning. One of the critical issues facing a maintenance system is that different maintenance checklists make it difficult to control a maintenance system, especially for several maintenance operators. It is also difficult for MRO companies to accurately estimate the number of operators needed to work in the company. For example, heavy service maintenance for a B727 aircraft takes around 14 days, if there are 48 maintenance operators available, while the same number can repair or service a Fokker F27 aircraft in four days [17].

Operator knowledge is a crucial element of the aircraft maintenance system, as this may affect MRO companies' operations resulting in maintenance delays and technical issues. The increasing number of aircraft components is becoming a significant problem for maintenance operators, bringing sharply into focus the value of such knowledge [18]. Maintenance costs and the demands of safety requirements necessitate that aircraft maintenance companies have multi-skilled operators to deal with aircraft maintenance problems (i.e. the maintenance schedule). Managers can help in this regard by directing maintenance operators (based on their skills) and splitting the maintenance task down into several parts, thus enabling operators to choose those parts/tasks they are familiar with. However, operators may face multi-task and multi- project environments that affect the maintenance project strategy [19]. Moreover, employers who have responsibility for aircraft maintenance tasks could encounter scheduling problems because operators work under multiple work orders and environmental conditions [20]. As timing becomes critical, the outcomes of overall maintenance work therefore could be significantly reduced or increased depending on the level of technical ability. That led authors to turnaround factor which is considered in the next section.

\subsection{Turnaround time}

MRO systems involve labor, knowledge requirements, and material equipment organizing aircraft components in the order of 12,000 units that must be supplied, causing the turnaround time factor [21].

At the other end of the spectrum, aircraft operation types can be categorised into long-haul or short-haul operation; the latter takes around 25 minutes. In contrast, long-haul flights take around an hour to service maintenance inspection, and because there is a short time between an aircraft's arrival and its departure, this can cause a turnaround time problem [22]. With regards to terms of the short time between an aircraft's arrival and its departure, the maintenance team need to build a strategy that involves arrival information (i.e. maintenance issues on previous similar planes and type of maintenance inspection check) as this can be a lengthy process. In addition, safety requirement rules recommend that maintenance operators do not walk around the plane for maintenance inspection until the engines have been completely shut down and cooled down, implying a serious safety risk. Requirements such as this can impact the turnaround time factor which in turn affects maintenance providers' and airline operators' strategies [23].

Furthermore, maintenance check types can cause turnaround time factors like line maintenance. In fact, maintenance operators may service around 20 aircraft or more in half an hour or an hour, which means that operators are rushing to prepare maintenance checklists for various aircraft. In trying to meet all maintenance demands, this can lead to two fundamental problems: maintenance costs for airline operators and maintenance scheduling problems for maintenance operators [24]. Maintenance checklist includes line and A, B, C, Dtype of checks. During the typical lifespan of an aircraft, it is not uncommon for aircraft to go through nearly 3000 tasks and checks as part of its overall maintenance. If maintenance operators lose 15 minutes during A-checks, this can amount to around 
one-month of delays for each aircraft, which in turn causes aircraft turnaround time factor problem [25].

\section{Analysis and Discussion}

According to previous studies, there were factors which affected MRO operation, based on their analyses and methodologies. Based on this, this section includes four sub-sections highlighting the most relevant issues affecting MRO companies' operations (OEMs, maintenance schedule, manpower, turnaround time and flight delays). This data is presented in the following sections and tables along with the number of authors who mentioned these factors.

\subsection{OEM suppliers and aircraft maintenance schedule.}

Table 3 shows two key factors which were highlighted by researchers and found to affect MRO scheduling (40.13\%) when compared to others. Most authors from this research used models to discover maintenance schedule problems, while interviews and model methods were used to collect information pertaining to OEM suppliers.

\begin{tabular}{lcccc} 
Table 3. OEM suppliers and aircraft maintenance schedule. \\
\hline Factors & $\begin{array}{c}\text { Case } \\
\text { study }\end{array}$ & Models & Interviews & Simulation \\
\hline$\# 1$ & 2 & 5 & 5 & 2 \\
$\# 4$ & 3 & 11 & 2 & 3
\end{tabular}

Table 4 addresses two factors linked to turnaround flight; around 15 papers show that these factors can affect the MRO operations. Furthermore, researchers use different methodologies to evaluate their research, and the models were more common in their study.

Table 4. Flight delays and turnaround time.

\begin{tabular}{lcccc}
\hline Factors & $\begin{array}{c}\text { Case } \\
\text { study }\end{array}$ & Models & Interviews & Simulation \\
\hline$\# 3$ & 3 & 3 & 0 & 0 \\
$\# 5$ & 1 & 4 & 1 & 1
\end{tabular}

Table 5 involves one factor that is trying to ascertain whether there is a major problem that might affect MRO operation; it is important to know how maintenance operators are dealing with aircraft maintenance. The keyword was the authors' used interviews method for manpower.

\begin{tabular}{lcccc} 
Table 5. Manpower. & & & \\
\hline Factors & $\begin{array}{l}\text { Case } \\
\text { study }\end{array}$ & Models & Interviews & Simulation \\
\hline$\# 2$ & 1 & 2 & 3 & 0
\end{tabular}

\subsection{Investigation methodology of individual factors}

\subsubsection{Manpower}

Table 5 presented the manpower factor that could have a direct impact on MRO company operations. This factor can cause by three elements: parking space, time consumption and skills [16,19]. As timing becomes critical, the outcomes of overall maintenance work therefore could be significantly reduced or increased depending on the level of workforce competence and technical ability (i.e. workforce performance). Most MRO companies have an expectation that reduced maintenance costs can be linked to the efficiencies in manpower performance during the maintenance period $[17,18]$.

There are therefore several areas to consider in this field, whilst also being mindful of identifying a useful research gap that is likely to add value and be of relevance to the existing body of previous data. In another area, previous data gathered from the literature review showed that researchers used the interview method to collect data; a strategy that may not have been useful because research questions may be unstructured. The other possibility was that participant answers might have been random or based on the current situation at their organization and, therefore, MRO companies' maintenance operation strategy might not develop. Only one case study method carried out by researchers for addressing human resources affect MRO operation that is inefficient analysis to say human resources can affect maintenance strategy. One of the key problems facing maintenance companies is to determine and correctly allocate the number of maintenance operators needed to service aircraft. In contrast, three interviews method carried out by researchers for addressing manpower effect MRO. MRO companies can impact their maintenance schedule by manpower, which can reduce or increase the turnaround time of an aircraft. In addition, flight delays caused by maintenance operators due to their level of skills, knowledge and any apparent weaknesses in training can also affect 
the profitability of airline companies. Hence the importance of having good, knowledgeable staff. This performance can be affected however, when operators require multi-task projects that will test different areas of expertise from MRO companies, which will affect the latter's maintenance project strategy.

\subsubsection{Fight delays and turnaround time}

Table 4 presented flight delays and turnaround time factors because most MRO companies' strategies are aimed at reducing time-consuming tasks for the aircraft maintenance process. Linked to the issue of time, reduced flight delays as a result of efficiencies in the maintenance process can help to lower airline operating costs [22]. Mathematical models can be used to estimate the impact of such factors based on flight hours, flight cycles and calendar days to calculate the number of flights. One possible approach for achieving a successful maintenance program is to divide maintenance tasks into six stages and map them [21,23,25]. This may not always be possible or practical if airline companies have a large number of aircraft, further sub-divided into aircraft types. That means researchers will need to adopt a case study method to examine this because having many aircraft in an airline company means a large volume of maintenance reports being available to researchers. However, researchers did not use interview methods for their research.

The large volume of maintenance reports, aircraft types and a large number of aircraft contribute flight delays and turnaround time. Such factors make the need to explore potential solutions for optimal maintenance strategies focused on efficient scheduling paramount, particularly if MRO companies and aircraft operators wish to avoid flight delays. Moreover, the daily pressures involved with adhering to maintenance checklists and meeting time deadlines for maintenance can exacerbate flight delays and the issue of aircraft maintenance schedule problems. Most existing research to date has not considered simulation model in their studies, hence the importance of having a simulation method to solve the maintenance schedule. Because the competitive pressures in the civil aviation sector and general levels of demand for air travel, the increase in the number of flights scheduled per day and flight turnaround times becoming shorter will help to guide this research (simulation method) in terms of exploring potential solutions for optimal maintenance strategies focusing specifically on scheduling to avoid flight delays.

\subsubsection{OEM suppliers VS maintenance schedule.}

The literature review showed that $40.13 \%$ of research papers presented OEM suppliers and maintenance schedule as the most relevant factors. Most operation problems for MRO companies stem from maintenance scheduling and OEM suppliers as these problems can lead to an increased number of flights scheduled per-day. This drives airline operators to carry out maintenance servicing based on aircraft checklists [6,7]. Tables 3 and 4 have shown that researchers relied on using the model method over other methods. It can be inferred that using a model to approach this problem is the best way forward. However, researchers tend to base their models on old data, so this may affect their findings.

The key to unscheduled maintenance problems lies with the OEM supplier because maintenance operators do not always envisage unexpected maintenance, which means operators have to spend time scheduling aircraft for maintenance, which in turn means waiting for spare parts to be delivered $[9,12,15]$.

Based on the analysis conducted in this study, a problem was observed with how researchers highlighted OEM suppliers affecting the operation of MRO companies because Tables 3 and 4 highlighted how some of the researchers used the interview method to determine OEM supplier problems which meant they gathered/compiled data based purely on the operators' opinion. As this view only provides one side of the issue, it could be argued that it is not correct to state that OEM suppliers solely affect MRO organizations' operations because sometimes the problems associated with spare parts delivery could actually be caused by MRO operators themselves due to factors such as budget and the type of spare part being requested.

Notwithstanding all of the above, the use of a model method in research might not help MRO companies' strategy when it comes to client requests, and it is clear that unexpected aircraft component failure is hard to analyze precisely using a model. This may explain why researchers used a simulation method. This method was based on types of maintenance checks by collecting real-data from the engine and then creating a simulation method 
that might help operators anticipate failures at the right time. However, the FAA, ICAO and EASA have cautioned against maintenance companies using technology as a basis for anticipating aircraft component failure [16]. Furthermore, the simulation systems used by researchers may not be sufficiently precise due to them working at different operating conditions.

From the literature reviewed, researchers used the case study method to collect data, especially to identify OEM suppliers' problems. Using a case study on just one or two airlines however, may not represent a useful methodology for MRO companies in terms of helping them to improve their maintenance strategy because fleet size was not considered.

\section{Conclusion and he future research}

Maintenance, Repair and Overhaul (MRO) within the aviation industry may be a complex task due to different requirements should be required during overflying stops. The aircraft visit various maintenance checks rely on the time of the upkeep checklist, which incorporates heavy maintenance or line maintenance. Per aircraft manufacturers that maintenance checks determined by flight hours, flight cycle and calendar months. That led maintenance operators to create their new strategy aims to cut back cost by specializing in a maintenance schedule and unscheduled, by developing the upkeep strategy for hosting aircraft in shorter maintenance periods that would reduce maintenance cost.

MRO companies faced some factors affect MRO operation, like manpower factor, which can be reduced or increase turnaround time of an aircraft. Flight delays can be caused by maintenance operators because their skills, knowledge and weakness of training could reduce the airline companies' profit. That is why some of the airline companies tend to have their own MRO service.

A significant result of the study is unexpected aircraft components failure that determines unscheduled maintenance. This action increase the maintenance cost for airline operators and time pressure for MRO providers. Furthermore, another factor is OEM suppliers' performance and capability of supply the spare parts and material on time without delay when MRO companies request maintenance requirements. The key point which might cause the delay factor is time spending to design one element of aircraft spare parts.
The risk of outsourcing maintenance still as one of the factor affect safety requirement, and OEM organization, OEM suppliers and MRO companies should follow safety requirements and be aware of these requirements.

The future research should focus on maintenance schedule problem on the light check, A-check and B-check by using Discrete Events Simulations to develop a framework. Because increasing the number of flight schedule per day and flight turnaround is short within less duration time for maintenance process that helps authors to build maintenance strategy for scheduling to avoid flight delay factor.

Moreover, the duration of the turnaround process of an aircraft build based on the type of flight operation that is a crucial point for researchers to use a model to expect the number of operators need for serving the aircraft.

\section{References}

[1] Ghanei S, AlGeddawy T. An Integrated Multi-Period Layout Planning and Scheduling Model for Sustainable Reconfigurable Manufacturing Systems: Journal of Advanced Manufacturing Systems; 2020. p.31-64

[2] Dinis D, Barbosa A, Teixeira AP. A supporting framework for maintenance capacity planning and scheduling: Development and application in the aircraft MRO industry. Production Economics. Lisboa: E-Publishing Inc; 2019. p.15.

[3] Mofokeng TJ, Marnewick A. Factors contributing to delays regarding aircraft during A-check maintenance. Technology $\&$ engineering management conference. Santa Clara; 2017.p $.185-190$

[4] Carlborg P, Kindström D, Kowalkowski C. The evolution of service innovation research. A critical review and synthesis. The Service Industries. 2014. p.373-98.

[5] Hsieh J , Chiu H, Wei C, Rebecca Yen H, Cheng Y. A practical perspective on the classification of service innovations. Services Marketing; 2013. p. 371-384.

[6] Goncalves C, Kokkolaras M. Modelling the relationship between aviation original equipment manufacturers and maintenance, repair and overhaul enterprises from a productservice system perspective. Product, Services and Systems Design. Vancouve; 2017.P. 389-398.

[7] Rahmawati F, Syarif RI, Nusantara HA. The Impact of Aircraft Spare Parts Import Duty Exemption on the MRO Industry's Competitiveness and Its Services Export. Jakarta: E-Publishing Inc; 2019.p.200-204

[8] Sarat S, Yifan LV, Hewitt A, Chalk R, Thomas W, Jordison D. Additive Manufacturing for the Aircraft Industry: A Review. Aeronautics and Aerospace Engineering. Auckland; 2019.p.11

[9] Phadnis SS, Fine CH. End-To-End Supply Chain Strategies: A Parametric Study of the Apparel Industry. Production and Operations Management. Selangor; 2017. p.2305-2322.

[10] Gu J, Zhang G, Li KW. Efficient aircraft spare parts inventory management under demand uncertainty. Air transport management. Windsor: E-Publishing Inc; 2015. p101-109.

[11] Ghadge A, Karantoni G, Chaudhuri A, Srinivasan A. Impact of additive manufacturing on aircraft supply chain 
performance. Manufacturing Technology Management. Bangalore: E-Publishing Inc; 2018.P. 846-848

[12] Saltoğlu R, Humaira N, İnalhan G. Aircraft scheduled airframe maintenance and downtime integrated cost model. Advances in operations research. Istanbu: E-Publishing Inc; 2016.p.2-16

[13] Woodlock J, Hydén H. How soft law serves as an instrumental mediator between professional norms and the hard law regulation of European civil aviation maintenance. Safety science. Lund; E-Publishing Inc; 2020. p.54-63.

[14] Vieira DR, Loures PL. Maintenance, repair and overhaul (MRO) fundamentals and strategies: An aeronautical industry overview. Computer Applications. Quebec: E-Publishing Inc; 2016.p.21-9.

[15] Al-Thani NA, Ahmed MB, Haouari M. A model and optimization-based heuristic for the operational aircraft maintenance routing problem. Transportation Research Part C: Emerging Technologies. Qatar: E-Publishing Inc; 2016. p.29-44.

[16] De Bruecker P, Beliën J, Van den Bergh J, Demeulemeester E. A three-stage mixed integer programming approach for optimizing the skill mix and training schedules for aircraft maintenance. Operational Research. Brussels: E-Publishing; 2018. p.439-52.

[17] Ren H, Chen X, Chen Y. Reliability based aircraft maintenance optimization and applications. Academic Press. London: E-Publishing; 2017. p.185-205.
[18] Sobbe E, Tenberg R, Meyer H. Knowledge work in aircraft maintenance. Technical Education. Berlin: E-Publishing Inc; 2016. p.1-18

[19] Kulkarni A, Yadav DK, Nikraz H. Aircraft maintenance checks using critical chain project path. Aircraft Engineering and Aerospace Technology. Bradford: E-Publishing Inc; 2017. p. $879-885$.

[20] Keleş B, Steins E, Erkoc M. Project Scheduling for MRO Work Orders Institute of Industrial and Systems Engineers. Coral Gables: E-Publishing Inc; 2017. p. 1944-1949

[21] McLaughlin P, Durazo-Cardenas I. Cellular manufacturing applications in MRO operations 2rd ed. Bedford: EPublishing Inc; 2013.p.254-259.

[22] Schosser M. Status quo of strategic network planning in airlines. In Big Data to Improve Strategic Network Planning in Airlines. Wiesbaden: E-Publishing Inc; 2020.p. 161-194.

[23] Kasava NK, Yusof NM, Khademi A, Saman MZ. Sustainable domain value stream mapping (SdVSM) framework application in aircraft maintenance. Johor Bahru: E-Publishing Inc; 2015.p. 418-423.

[24] Eltoukhy AE, Wang ZX, Chan FT, Chung SH, Ma HL, Wang XP. Robust Aircraft Maintenance Routing Problem Using a Turn-Around Time Reduction Approach. Hong Kong: EPublishing Inc 2019 .p. 1-14

[25] Mofokeng TJ, Marnewick A. Factors contributing to delays regarding aircraft during A-check maintenance. Technology and engineering management. Johannesburg: E-Publishing Inc; 2017.p. 185-190. 
$2020-10-26$

\title{
Scheduling challenges within
}

maintenance repair and overhaul

operations in the civil aviation sector

\author{
Albakkoush, Salah
}

SSRN

\begin{abstract}
Albakkoush S, Pagone E, Salonitis K. (2020) Scheduling challenges within maintenance repair and overhaul operations in the civil aviation sector. In: TESConf 2020 - 9th International

Conference on Through-life Engineering Services, 3-4 November 2020, Online, Cranfield UK https://doi.org/10.2139/ssrn.3718006

Downloaded from Cranfield Library Services E-Repository
\end{abstract}

